\title{
Thermodynamics and Gradient Manipulation Mechanism in Entrepreneurial Actions
}

\author{
David Leong $^{1}$ \\ ${ }^{1}$ University of Canberra, University of Canberra, Australia \\ Correspondence: David Leong, University of Canberra, University of Canberra, Bruce ACT 2617 Australia. \\ E-mail: davidskleong@gmail.com
}

Received: May 18, 2021

Accepted: July 12, 2021

Online Published: July 20, 2021

doi:10.5539/ijbm.v16n9p29

URL: https://doi.org/10.5539/ijbm.v16n9p29

\begin{abstract}
Entrepreneurship researches started to have traction at the start of 1980 and underwent paradigmatic shift. However despite the varied veins of exploration from opportunities to innate traits, entrepreneurship literatures have yet developed a unifying conceptualization and theory with key concepts that can clearly explain why entrepreneurs act the way they do? What inspires them to action? What seduce them to move at all? This paper intends to relate the study of entrepreneurship, entrepreneurial actions and activities with references to thermodynamic and energy gradient manipulation mechanism. Studying business ventures from a process view in an attempt to reconstruct the entrepreneurial process by illustrating a range of relevant perspectives from energy gradients in naturally occurring chemicals and suspension coils, this paper hopes to pull together a unifying theory on entrepreneurship basing on the forces at work with thermodynamic concepts and expressions with gradient-manipulation mechanism to explain the entrepreneurial action-motion phenomena. The gradient-manipulating mechanism and thermodynamic expressions thus become the "nature" invisible hand that operates the motion of actions. Kirzner's theory of entrepreneurship explains the coordination of markets and of knowledge. It is that knowledge, the recognition of the opportunities in the actual imperfect markets that triggers the gradient-manipulation mechanism.

The findings of this paper suggest that entrepreneurial actions are force-driven by the lure of profits to select of best pathways and means to achieve the ends. The idea that entrepreneurial actions are the results of the play of forces with thermodynamic forces at work is a powerful suggestion in the finding of this paper.
\end{abstract}

Keywords: entrepreneurship, thermodynamics, tension, gradient-manipulation, disequilibrium, dissipation, potential

\section{Introduction}

The field of entrepreneurship has been shaped in a rather disconnected manner, and its conceptual evolutions into varied theoretical strands is by borrowing, constructing and adapting the theoretical and conceptual work from fields such as sociology, psychology, anthropology, marketing, management, finance, organizational behaviours, and engineering (Kuratko et al., 2015). In this paper, thermodynamics will be used to explore the forces at work in entrepreneurship and in addressing the question of what causes entrepreneurial actions.

The notion that entrepreneurial opportunities exist "out there" independently and objectively is increasingly under serious debates by scholars who argue that opportunities do not pre-exist objectively but are actively created through subjective processes of social construction. In this paper we bring into ambit of our discussion such criticisms advocated by the creation approach but resist abandoning the pre-existing reality of opportunities (Ramoglou \& Tsang, 2015). In here, we are asserting that opportunities' appearance and presentment to the entrepreneurs - how they are perceived and recognized are not as critical as how they motivate the entrepreneurs to act. We are arguing that the appearance can come in many forms- objectively or subjectively constructed. The larger question for the entrepreneurs is - "to act or not to act" with the local appearance of opportunities. The aim of this paper is to address why do they act and how do they act, thus attempting to explain entrepreneurial actions in thermodynamics expressions taking the view of Ludwig Von Mises in "Human Action: A Treatise on Economics" (Mises, 1949) and Kirzner's "Competition and Entrepreneurship” (Kirzner, 1973b). 
Entrepreneurs act in response to the recognition of opportunities under conditions of uncertainties or differing degrees of risks. With the definition of Knightian uncertainty as a precursor to profit-making, from the perception, identification, recognition, description, the operationalization of uncertainty as a construct continue to exhibit conflicting definitions, eliciting debates on operating within an environment situated with risks and uncertainties. The construct with its tautological measures, and unwitting conflation is situated along the spectrum of ignorance and unknowingness (Townsend et al., 2018). Within the critical boundary conditions of uncertainty, why do entrepreneurs act the way they do and what is the specific trigger to purposeful actions with means to culminate to the achievement of the ends? This paper therefore explores the entrepreneurial actions under such uncertain conditions, with thermodynamics principles and gradient-manipulation mechanism to refine the entrepreneurial phenomena by expressing them in a more formal scientific language with all the assumptions for scientific tractability. The entrepreneurial element of human actions defies tractability with their 'liberty of spontaneity' (Foot, 1957). Human actions are probabilistic as they are acted in free action and free will (Watson, 1987). Mises and Kirzner in their development of their respective disciplines sought to reemphasize that the market is a process operating in an open-ended universe and cannot explain the operation of the market and the adjustments of the price system, or in the study of entrepreneurial actions in relations to opportunities without recourse to the entrepreneurs (Boettke \& Sautet, 2012).

The "invisible hand" operates "naturally" in response to entrepreneurial opportunity because of market imperfections and disequilibrium. The operations of the "invisible hand" is not relying on the classical theorem of competitive equilibrium (McKenzie, 1981); as the trigger for the "invisible hand" to act is due to the gradient-manipulating mechanism that operates in a state of disequilibrium. The "invisible hand" does not function in economic equilibrium since the state of equilibrium is a state of non-action; in such state, the "invisible hand" does not move. The aim of this paper is to explore the mysterious forces directing the course of entrepreneurial actions with grounded scientific references and thermodynamics terms.

The research focus of this paper is to explore the reasons and rationales behind each entrepreneurial action and motion in the process. The ensuing discussion shall be discussing entrepreneurial actions on thermodynamic terms and definitions.

\section{Perspectives of Actions in Entrepreneurship}

Entrepreneurs are economic actors more precisely imperfect actors in an imperfect world of frictions, uncertainty, and human ignorance. In an attempt to gain a contextually richer understanding of how the invisible hand operates in coordinating, combining, recombining resources (Bessant, \& Trifilova, 2017) through the vast array of economic exchanges and activities in the actual imperfect world, the study of entrepreneurial action is to be explored in the context of disequilibrium. The "invisible hand" with a mysterious force works precisely because of the imperfections in prices, discrepancies and disequilibrium therefore opportunities arise. In short, entrepreneurial actions are triggered by differentials arising from economic disequilibrium.

"There is nothing "normal" in profits and there can never be an "equilibrium" with regard to them. Profit and loss are, on the contrary, always a phenomenon of a deviation from "normalcy," of changes unforeseen by the majority, and of a "disequilibrium." They have no place in an imaginary world of normalcy and equilibrium.' (Mises, 1949, p. 295)

Are entrepreneurial actions responding to a set of signals and stimuli? Can they be interpreted in thermodynamical interpretations which postulate instantaneous adjustments and tactical manoeuvrings in the means to achieve the ends for the derivation of profits? Embedded within opportunities are prices signals to entrepreneurs of the relative scarcities of the goods and services. When the price is relatively high, it can be inferred that the commodity in question is relatively scarce and thus must be economized in its use, whereas when the price is relatively low, it can be inferred that the commodity in question is relatively abundant and thus can be utilized more. Prices aid decision makers in making decisions by providing ex ante knowledge of the situation (Boettke \& Sautet, 2012). However, the price-signalling mechanism also provides ex post knowledge to the entrepreneurs in the form of profit and loss statements of businesses. When entrepreneurs buy low and sell high, the market communicates that the prior commitment and decision was anchored in the right direction to be profitable, whereas in the situation where it is transacted at a high and must sell low, an error in judgment is revealed since loss is incurred. 'The very discrepancy between the ex-ante expectations set by the array of prices at the moment of decision, and the ex post realizations of profit and loss sets in motion the discovery of better ways to arrange economic activities' (Boettke \& Sautet, 2012, p. 36). Where there is a price discrepancy, a gradient exists between the high-low points. The gradient-manipulation mechanism is therefore the act to manipulate the gradient for profit. It is through the price-signalling system within the opportunity that triggers 
the gradient-manipulation mechanism through a select set of entrepreneurial actions and activities which are constant adjustments, economic coordination and continual learning. Hence, the movement of prices are generally misaligned between demand and supply, in a way "false" or in nonequilibrium ways giving rise to arbitrage with gradient-manipulation mechanism invoked to level off the differential to derive profits. Yet, at the same time the price-signals in opportunities are informationally and motivationally useful in guiding and coordinating economic activity through time (Boettke \& Sautet, 2012). In this context, it is important to note that profit-seeking entrepreneurs do not tolerate any false prices and will look for ways to equilibrate and to seek profits from them through gradient-manipulation mechanism. The dissipative actions on the potential profits loaded in the spread of the gradient is persistent but the removal of the gradient makes the dissipative response disappear.

So when opportunities are informationally and motivationally useful in guiding and coordinating entrepreneurial actions, how are these information and knowledge, or lack of them, to be inferred? The price-signalling mechanism in opportunities, in its inability to convey all information, creates the incentives to discover what is missing. The entrepreneurial task is about discovering information and knowledge to reduce the level of ignorance (Boettke \& Sautet, 2012).

'Ignorance is always present. It is not, however, of the same nature in the open-system as it is in the closed competitive equilibrium. In the former, ignorance is radical because it pertains to ignorance itself: individuals do not know what they do not know. This implies a world where "true uncertainty" exists, that is, where future events are truly unpredictable. It is because of this context of radical ignorance and true uncertainty that the Hayekian economic problem is real. Assuming the problem away, as competitive equilibrium does, reduces the economic problem to a mechanistic issue (i.e., which prices clear markets?), as opposed to an epistemic one (i.e., how can the system self-correct?). In this context, the entrepreneurial function, this unique human characteristic, offers a response to the challenge of radical ignorance. The veil of ignorance is continually under attack because human imagination is always at work. It is important to emphasize that human imagination, the possibility of sheer creation of information, is the principal characteristic of the entrepreneurial function. However, in the social context, creativity is necessary but often not sufficient. What is also needed is a compass to determine, as Joseph Schumpeter emphasized, that invention (i.e., creativity) is also innovation (i.e., socially useful creativity).' (Boettke \& Sautet, 2012, p. 41)

This compass, described, is therefore directing the entrepreneurial actions to level off any price differentials and discrepancies through socially useful creativity and innovation under conditions of varying level of uncertainties. Perception of the information/ knowledge, despite its incompleteness sometime to the point of absolute uncertainty and ignorance, must be contingent on the purposeful entrepreneurial actions that follow without which no profits can be derived.

Perception, opportunity and profit are therefore integral in the studies in the theory of entrepreneurship.

'Human action, in the sense developed by Mises, involves courses of action taken by the human being 'to remove uneasiness' and to make himself 'better off'. Being broader than the notion of economizing (i.e., maximizing), the concept of human action does not restrict analysis of the decision to the allocation problem posed by the juxtaposition of scarce means and multiple ends. The decision, in the framework of the human action approach, is not arrived at merely by mechanical computation of the solution to the maximization problem implicit in the configuration of the given ends and means. It reflects not merely the manipulation of given means to correspond faithfully with the hierarchy of given ends, but also the very perception of the ends-means framework within which allocation and economizing are to take place... Mises' homo agens ... is endowed not only with the propensity to pursue goals efficiently, once ends and means are clearly identified but also with the drive and alertness needed to identify which ends to strive for and which means are available.' (Kirzner, 1973, p. 33)

In Kirzner's approach, where opportunities for exploitation involve creating and mobilizing resources or some combinations of both, the intent is driven by the motive- entrepreneurial profit. The lure of profit will lead entrepreneurs to discover these opportunities and pursue them unrelentingly until, through the competitive entrepreneurial process, resources have been relocated in an equilibrium that eliminates both the profit opportunities. This is the trigger point for gradient-manipulation where the entrepreneurial actions capitalize on the misallocation and disequilibrium to capture profits to a state of certain equilibrium. The process depends heavily on the lure of profits, with the ingenuities, creativity and innovation of means to exploit the opportunity as the targeted end. 
'Entrepreneurship is manifested in short-run movement fully as much as in long run developmental changes and is exercised by the imitators (who move in to exploit the opportunities exposed by the activities of the innovators) fully as much as by the innovators themselves. For us entrepreneurship ceases only when imitative activity has succeeded in squeezing out all the profit opportunities. We see the process whereby an above-equilibrium price is beaten down towards equilibrium as an entrepreneurial process; it requires entrepreneurial alertness to the realities of the situation to adjust to the true eagerness (or rather, relative lack of eagerness) of prospective buyers. In fact it is precisely the short-run market processes which are responsible for the ever-present agitation tending towards market equilibrium positions that we wish to illumine by our emphasis on entrepreneurship' (Kirzner, 1973, p. 128)

The process of equilibrating the perceived anomaly, discrepancy and price differential in the market and this recognized opportunity that exist in a state of disequilibrium will be "beaten down towards equilibrium" through gradient-manipulative mechanisms; agitating and acting towards market equilibrium not just by the entrepreneurs but the horde of imitators. Perspectives of actions in entrepreneurship is really about the agitations, in some self-organization manner by the entrepreneur as the main agent, and the imitators in an entrepreneurial process, situated in risks and uncertainties at different time, different space to beat down towards equilibrium.

\section{Situation in Risks and Uncertainties}

Risks and uncertainties are unavoidable in entrepreneurship and they exist in all phases of the entrepreneurial process of differing degree and scale. Entrepreneurship is therefore about taking into account the abilities to deal with the disequilibria presented by these risks and uncertainties. 'Risk and uncertainty are ever present in the optimizing behaviour here under consideration. How much of the observed difference in responses is a consequence of the difference in risk and uncertainty (including the difference in preferences to bear them) is very difficult to determine.' (Schultz, 1975, p. 835). Risks and uncertainties remain fundamental to entrepreneurial actions.

Most decisions in entrepreneurial action are made under conditions of risk and uncertainty to the extent that there is other decisions that are made when risks are unknowable (Huang \& Pearce, 2015) and this stymies the entrepreneurs to be able to predicate their actions with any certainties. 'The construct as a synonym for all manner of "unknowingness." Although unknowingness - which spans the entire landscape of human consciousness lying between ignorance and certainty - truly is ubiquitous, uncertainty is merely a subset of unknowingness.' (Townsend et al., 2018, p. 660). In absolute "unknowingness" and uncertainty, with "uninsurable" risks (Knight, 1921), the entrepreneurs' actions are premising on "gut feel" or "trust the gut" (Huang \& Pearce, 2015), With insurable risks, entrepreneurs can predicate actions on probabilities because while the actual outcome is unknown, the range of possible solutions is contemplatable with its limits on the combinatorial and probabilistic sets. Thus, risky problems are "insurable"-meaning that risks can be hedged, pooled, or otherwise compensated by paying insurance to cover the potential occurrence of unfavourable outcomes - whereas certain other types of uncertainty are a priori irreducible and, therefore, "uninsurable" because there are no immediate market pricing mechanisms to cover unforeseen eventualities (Townsend et al., 2018).

Uncertainties, however, are not deterrents to the point of putting the entrepreneurs on an aversive state but in fact earn their rights to profit because of their risk-taking attitude and persistence in an active agitation to find the means to achieve their profitable ends. Knight in (Knight, 1921) stressed the importance of uncertainty bearing as a key reason for the their rights to profit as a reward for entrepreneurial venture bearing the risks of affordable loss (Dew et al., 2009). Affordable loss is a cognitive and behavioural attitude towards risk-taking and the willingness to be subjected to loss in a wrong bet on a course of action. - a plunge decision, as defined in (Dew et al., 2009) where its behavioural economics intersecting with affordable loss heuristic. Uncertainties constitute a constant struggle confronted by entrepreneurs since they are ubiquitous to a greater or lesser degree at different point in time and in space. Uncertainties and entrepreneurial actions are inextricably linked to the prospect of a promising and profitable venture. Mises further added that every new datum brings about a fresh reshuffling of the whole possibilities and the dealing with uncertainty of future conditions is always problematic to entrepreneurs since they have no constancy nor continuity.

'The fundamental deficiency implied in every quantitative approach to economic problems consists in the neglect of the fact that there are no constant relations between what are called economic dimensions. There is neither constancy nor continuity in the valuations and in the formation of exchange ratios between various commodities. Every new datum brings about a reshuffling of the whole price structure. Understanding, by trying to grasp what is going on in the minds of the men concerned, can approach the problem of forecasting future 
conditions. We may call its method unsatisfactory and the positivists may arrogantly scorn it. But such arbitrary judgments must not and cannot obscure the fact that understanding is the only appropriate method of dealing with the uncertainty of future conditions.' (Mises, 1949, p. 118)

In the real world of entrepreneurship with imperfect information and knowledge that may be hazily defined, the interpretation of the opportunity potential and the reality in fact is a product of social construction with self-organization (Shir et al., 2019), co-creation (Pitelis, 2012) and other dynamic interactions of various causes (McKelvey, 2004) to culminate in generative emergence (Lichtenstein, 2014). These higher order emergence derived from the interactions among key independent variables like available resource bundles (Lichtenstein \& Brush, 2001), asymmetric market information (Atuahene-Gima, 1996), competitors (Hattwick, 1979) and imitators produce the nonlinearities and multifinalities. The multifinalities are different, equally viable outcomes emerging from probable causes (McKelvey, 2004). The probabilistic outcomes of complex environments with the dynamic interactions of various causes shall be discussed on thermodynamic terms - which is the basis for thermodynamic characterisation of the generative emergence as a result of interdependencies between the dynamic variables (Cohen et al., 2008) in the entrepreneurial process.

\section{Constructing a Processual Framework - Entrepreneurial Process in Market Process}

'The notion of market as a process in Mises's work rests on the idea of interconnectedness among human activities (i.e., "connexity" as Mises puts it). The connexity of the market can only be explained if one views the market as a process. The mechanism that creates the connexity of human activities is entrepreneurial monetary calculations. ... entrepreneurs are able to discover opportunities that may require, for their exploitation, a large division of labour and knowledge. The simultaneous exploitation of numerous entrepreneurial discoveries creates a concatenation of affairs among the various economic actors because entrepreneurs bid resources away from their alternative uses. This bidding process (based on entrepreneurial monetary calculation) creates interconnectedness among human activities. Prices are not isolated elements in the marketplace; they result from the complex relationships that prevail at any moment in society, and upon which the material, scientific and technological advances of western civilization rests.' (Boettke \& Sautet, 2012, p. 37)

Entrepreneurial process functions within the market process as entrepreneurial discoveries create a concatenation of affairs and interdependence among the various economic actors and resource bundles available in the environment in a self-organization manner based on selective process of entrepreneurial profit calculations. 'The selective process never stops. It goes on adjusting the social apparatus of production to the changes in demand and supply. It reviews again and again its previous decisions and forces everybody to submit to a new examination of his case. There is no security and no such thing as a right to preserve any position acquired in the past. Nobody is exempt from the law of the market, the consumers' sovereignty.' (Mises, 1949, p. 308). On Mises's terms and interpretations of entrepreneurial process and actions in 1949, much has been developed with entrepreneurial process (Bygrave, 1993) (Lichtenstein, 2014) (Davidsson \& Gruenhagen, 2020).

Our first challenge is how to conceptualize the entrepreneurial journey as a unified emergent process interspersed with entrepreneurial events that are created as a result of ad-hoc exogenous and endogenous elements. Either internal perturbations - self-generated motivation and passion (Frese \& Gielnik, 2014) or externalities like shocks (Shepherd et al., 2000), stressors (Wei et al., 2015) and triggers (Ireland et al., 2003) that emerge unpredictably in the environment. The impacts by such external factors or internal factors therefore denote the needs for change and adaptation by the entrepreneurs in the entrepreneurial event. For this purpose, this paper brings together entrepreneurial research on the embeddedness of internal passions and the perturbations in the ecosystem to develop a framework to better understand the connection of such perturbations to the way they finally respond, react and enact on the emergent events in the entrepreneurial journey. This paper argues that it is the generative set of motions and entrepreneurial actions that are taken that extends the play of the entrepreneurial curve, despite challenges and obstacles.

The entrepreneurial sine-curve is therefore defined, in this paper as the movement in the entrepreneurial pathway captured with reference to time. The entrepreneurial intensity (Sexton \& Morris, 1996) is measured by the amplitude expressing the force of action or the level of the entrepreneurial energy (Leong, 2020)(Leong, 2021) in that phase of the process. The frequency measures the repetition of actions. The actions are the responses that will shift the entrepreneur's trajectory in that event impacted with an external or internal perturbation. The key observable outputs in this case- frequency and amplitude- are determinants in the mathematical sinusoidal characterization of the entrepreneurial process/ pathway/ journey. At each juncture and entrepreneurial event, the entrepreneurs, in a way, through whatever available means and resources need to mitigate the impacts of the 
perturbations. It is a play of probabilities and with each play, the entrepreneurs will not know deterministically any outcome. Each play is a roll of the dice based on the ensuing actions to be taken.

The conceptualization of time and movement (i.e., actions) are core to entrepreneurial venturing. The actions taken by the entrepreneurs, whether on a creation and co-creation (Pitelis, 2012) or alternately self-organization (Wiklund et al., 2019), in the process characterized by fluctuations, irreversibility, non-linearity and in an inherently unpredictable environment with instabilities (Schindehutte \& Morris, 2009) is the core of this paper theorizing.

A framework with process theories will sharpen the understanding of entrepreneurship from a more holistic perspective. Generative emergence theory propounded by Lichtenstein frames "the-coming-into-being" and emergent phenomenon - it describes how new entities are created, how a new order comes into being in the entrepreneurial process. In the emergence theory, change and transformation are core and it explains the phenomenon of creation (Lichtenstein, 2020). The rapidity, relentless, irreversibility and nonlinear change and transformation fundamentally mark every point in the processual entrepreneurial journey (Chia, 1999). Granting that change and transformation are imminent part of generative emergence, how should the change itself be viewed? The nature of change with reference to order, stability and organization may need to be recast with reference to disorder and disequilibrium

Entrepreneurial actions amidst disorder and disequilibrium is pivoting on interlocking acts of 'arresting', 'locating', 'regularizing' and 'stabilizing' arbitrary segments of an intrinsically fluxing and transforming 'real' into a coherent, lived entrepreneurial process (Weick \& Quinn, 1999). The operative word is "stabilizing" as the system is in constant state of movement in an attempt to equilibrium in a far-from-equilibrium state. In (Lichtenstein, 2007) Lichtenstein identifies two distinct driver of emergence (1) far from equilibrium dynamics that trigger order creation and (2) adaptive tension or in Lichtenstein's own definition "opportunity tension" which can push a system towards instability which can also trigger emergence phenomenon. Entrepreneurs, in their pursuit to chase for deals and opportunities for profits (Dana et al., 2008) look out for arbitrage-able opportunity where they can capitalize on the gap. To enable the discovery of opportunities, the search is for the $\mathrm{gap} /$ tension and with the identification and recognition of the tension, this generates actionable exploitations to reduce the inherent tension and to derive profits from the differential. This tension presents an economic energy differential (Lichtenstein, 2009) and "energy differentials need to have a motivational valance attached before they can be expected to be felt by agents" (McKelvey, 2001). Such driving system in search of the economic energy differential to profit from has fascinating overlaps with natural dissipative structures:

'the only process in selection ... competing to degrade available energy gradients. The origin of life should not be seen as an isolated event. Rather it represents the emergence of yet another class of processes whose goal is the dissipation of thermodynamic gradients. Life should be viewed as the most sophisticated (until now) end in the continuum of development of natural dissipative structures from physical to chemical to autocatalytic to living systems.' (Schneider \& Kay, 1994, p. 36)

The nonequilibrium state, with the presence of energy-rich gradients waiting to be dissipated for profits, in thermodynamical terms will be discussed with reference to entrepreneurial venturing in search of energy-rich gradients.

\subsection{Thermodynamic Preliminaries}

The thermodynamics principles of various evolving systems from chemical, biological and physical systems to complex living systems where 'our thermodynamic description of living systems fits comfortably into the present day molecular-genetic research program. The importance of the gene and its role in morphogenesis, speciation, and in carrying the message of evolution forward is vital.' (Schneider \& Kay, 1994, p. 46) and we can conclude that they involve similar processes as entrepreneurial ventures which are phenomenological manifestations of the second law of thermodynamics. In this paper, a reformulated second law of thermodynamics is taken in relations to the study of entrepreneurial venture will be discussed in nonequilibrium regions, where nonequilibrium is described in terms of gradients maintaining systems at some distance away from equilibrium.

'In this context, the second law mandates that as systems are moved away from equilibrium, they will take advantage of all means available to them to resist externally applied gradients. Our expansion of the second law immediately applies to complex systems in nonequilibrium settings unlike classical statements which are restricted to equilibrium or near equilibrium conditions. Away from equilibrium, highly ordered stable complex systems can emerge, develop, and grow at the expense of more disorder at higher levels in the system's hierarchy.' (Schneider \& Kay, 1994, p. 46) 
When the second law of thermodynamics and the tendency for an isolated system to increase in entropy or disorder comes into play, Schrödinger explained that the very act of living is the perpetual effort to stave off disorder as long as can be managed. He illustrated with examples to show how living things do that at the macroscopic level by taking in free energy from the environment and by releasing heat into their surroundings but avoid running out of energy by consuming food- the technical definition is metabolism. The ultimate source of "negative entropy" on Earth, wrote Schrödinger, is the sun.

'Between the earth and sun, however, there is a colossal temperature difference; between these two bodies, energy is thus not at all distributed according to the laws of probability. The equalization of temperature, based on the tendency towards greater probability, takes millions of years, because the bodies are so large and are so far apart. The intermediate forms assumed by solar energy, until it falls to terrestrial temperatures, can be fairly improbable, so that we can easily use the transition of heat from sun to earth for the performance of work, like the transition of water from the boiler to the cooling instillation. The general struggle for existence of animate beings is therefore not a struggle for raw materials-these, for organisms, are air, water and soil, all abundantly available-nor for energy which exists in plenty in any body in the form of heat (albeit unfortunately not transformable), but a struggle for entropy, which becomes available through the transition of energy from the hot sun to the cold earth. In order to exploit this transition as much as possible, plants spread their immense surface of leaves and force the sun's energy, before it falls to the earth's temperature, to perform in ways yet unexplored certain chemical syntheses of which no one in our laboratories has so far the least idea. The products of this chemical kitchen constitute the object of struggle of the animal world.' (Schneider \& Kay, 1994, p. 35)

Energy gradients, entropy and dissipation are the nonequilibrium drivers that give rise to highly ordered stable complex systems - that emerge, develop, and grow at the expense of more disorder at higher levels in the system's hierarchy. Recent studies have also shown something similar at the microscopic level where many cellular processes - ranging from gene transcription to intracellular transport-have underlying nonequilibrium drivers (Ornes, 2017). 'The emergence of coherent self-organizing structures is an expected response of a system as it attempts to resist and dissipate externally applied gradients which would move the system away from equilibrium. The term dissipative structure takes on a new meaning. No longer does it mean just increasing dissipation of matter and energy, but dissipation of gradients as well.' (Schneider \& Kay, 1994, p. 33-34). The gradient-reducing nature of self-organizing systems is similar to the entrepreneurial self-organizing which shall be explored. 'The thermodynamic imperative of the restated second law is that these systems will strive to reduce this gradient by all physical and chemical processes available to them. Thus, ecosystems will develop structures and functions selected to most effectively dissipate the gradients imposed on them while allowing for the continued existence of the ecosystem.'(Schneider \& Kay, 1994, p. 26).

'All natural processes can be viewed in light of the second law and in all cases this one-sided aspect of nature is observed. Heat always flows spontaneously from a hotter reservoir to a colder reservoir until there is no longer a temperature difference or gradient; gas will always flow from high pressure to low pressure until there is no longer a pressure difference or gradient.' (Schneider \& Kay, 1994, p. 28). These natural process show the predictable nature's patterns arising from gradient-manipulation that spur the continued existence and propagation of systems. The degree to which a system has been moved from equilibrium is measured by the gradients imposed on the system.

'The thermodynamic principle which governs the behaviour of systems is that, as they are moved away from equilibrium they will utilize all avenues available to counter the applied gradients. As the applied gradients increase, so does the system's ability to oppose further movement from equilibrium.' (Schneider \& Kay, 1994, p. 29)

'A simple example of this phenomena is the Benard cell. The experimental apparatus for studying the Benard cell consists of a highly instrumented insulated container enclosing a fluid. The bottom of the container is a heat source and the top is a cold reservoir. When the fluid is heated from below it resists the applied gradients (AT) by dissipating heat through conduction. As the gradient is increased, the fluid develops convection cells. These convection cells increase the rate of dissipation.' (Schneider \& Kay, 1994, p. 29).

\subsection{Dissipative Structures and Gradient-Manipulative Mechanism}

In here, we can examine the behaviour of dissipative structures under the restated second law of thermodynamics. Prigogine showed that dissipative structures self-organize through fluctuations and instabilities characterized by a structural and functional order and by a low value of entropy (Prigogine \& Lefever, 1968). 'Fundamental conceptual problems that arise from the macroscopic and microscopic aspects of the second law of thermodynamics are considered. It is shown that nonequilibrium may become a source of order and that 
irreversible processes may lead to a new type of dynamic states of matter called "dissipative structures." The thermodynamic theory of such structures is outlined. A microscopic definition of irreversible processes is given, and a transformation theory is developed that allows one to introduce nonunitary equations of motion that explicitly display irreversibility and approach to thermodynamic equilibrium. 'The inclusion of thermodynamic irreversibility through a nonunitary transformation theory leads to a deep alteration in the structure of dynamics.' (Prigogine, 1978, p. 785).

Dissipative structures can exhibit life-like features and activities such as collective and coordinated behaviours (De Bari et al., 2020). 'Electrical dissipative structures can functionally coordinate their behaviours to maximize the rate of entropy production. Coupled oscillating electrical dissipative structures exhibit in-phase and anti-phase coordinative modes characteristic of biological coupled oscillators. Chemical swimmers form collective flocks with emergent properties, including sensitivities to magnetic and thermal fields, and rudimentary navigational capabilities ' (De Bari et al., 2020, p. 1)

On a biological level, dissipative structure can also be observed in organisms. Organisms may be in reciprocally causal relationships with their environments or with other organisms, coupled through the exchange of information and or forces which are dynamically interacting. Behaviour is emergent from this dynamic interaction, whether the organism acts alone or with other organisms, they are in a heterogenous interplay. Both approaches then postulate circularly causal or reciprocal relationships between actors and their environments, and the emergence of stable, self-organized, dynamical modes of interaction. This same organism-environment reciprocity and interactivity enables the functional coordination between organisms - each organism modulates the environment and the available information, in turn guiding the activity of the organism and others via epistemic reciprocity (Figure 1). Self-organization is not restricted to a biological phenomenon, but apply to a broad range of non-equilibrium physical systems, including organic ones. One approach to the physics of self-organization is Prigogine's dissipative structures theory, which focuses on the role of entropy producing (i.e., dissipative) processes that drive the production of stable dynamical modes in non-equilibrium systems (De Bari et al., 2020).

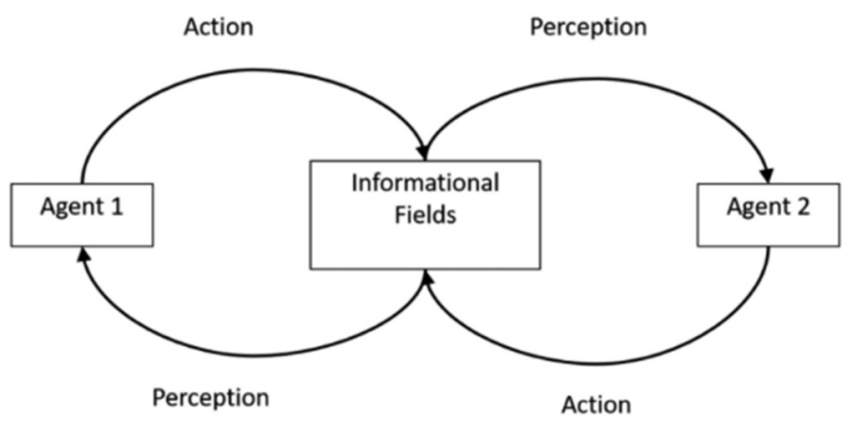

Figure 1. Epistemic reciprocity

Source: De Bari et al., 2020, p. 3

In Figure 1, Individual perception-action mutualities couple an organism to its environment via a reciprocal relationship with informational fields. Multiple organisms may become coupled when they share and jointly structure such informational fields

In (DeLanda, 2011) in the chapter under "Artificial Chemistries and the Prebiotic Soup", the discussion on the physical and chemical gradients have great relevance to our discussion of gradient manipulation and tension reliefs in entrepreneurship. Gradients of properties like temperature (harsh conditions within which entrepreneurs operate within), density (level and state of competition) or speed cause spontaneous organization (self-organization) of the molecules (entrepreneurs) into collective patterns of flow. So the collective patterns of flow arise from natural play of gradients. In this section, we are theorizing that actions taken by entrepreneurs are very much influenced by the same flow patterns in natural physical and chemical gradients and these responses are resultants of tension reliefs.

'Chemical gradients like these are thought to have played an important role in the dynamics of the prebiotic soup. But in addition to new gradients exploring the primordial medium in which living creatures first emerged involves considering interactions in which different molecules can bond and form a new compound or, on the contrary, in 
which compounds can be broken down into their component parts. This leads not only to much larger combinatorial spaces with atoms and molecules of different species entering into innumerable possible combinations, but more importantly, forces us to invent new means to explore possibility spaces that are intrinsically open-ended: if chemical interactions lead to the formation of a compound not originally present in a mixture, and if this compound is produced in large enough quantities to yield a concentration gradient, then the very nature of the mixture as well as that of its possibility space is changed. In other words, the inherent open-endedness of chemical interactions allows possibilities not originally present in a space to be subsequently added to it.' (DeLanda, 2011, p. 37)

Chemical gradients also result in dissipative autocatalytic reactions, which are commonly found in simple inorganic chemical systems such as protein synthesis reactions, or phosphorylation, polymerization and hydrolytic autocatalytic reactions. Autocatalytic reactions systems operates as positive feedback where the activity of the system or reaction augments itself in the form of self-reinforcing reactions. (e.g. A catalyses the formation of $\mathrm{B}$ and $\mathrm{B}$ accelerates the formation of $\mathrm{A}$; the overall set of reactions is an autocatalytic or positive feedback cycle). Autocatalysis sets in motion a self-generative iterative sequence- the activity of any element in the operative cycle begets greater activity in all the other elements, thus, stimulating the aggregate activity of the whole cycle. Such self-reinforcing catalytic activity is self-organizing and is an important way of increasing the dissipative capacity of the system. Cycling and autocatalysis is a fundamental process in nonequilibrium systems (Schneider \& Kay, 1994). The notion of dissipative systems as gradient dissipators holds for nonequilibrium physical, biological and chemical systems and describes the processes of emergence and development of complex systems. Not only are the processes of these dissipative systems consistent with the restated second law, it should be expected that they will exist wherever there are gradients.

Such commonalities in natural phenomenon explaining energy existing in the physical and chemical gradients spurring entrepreneurial efforts to pursue, through sets of actions and activities to unleash and dissipate the energy in the gradients can unlock many of the puzzles in entrepreneurial venturing explaining the pathway development and trajectories. An implication is that an effective entrepreneur ought to be able to not only perceive and recognise those opportunities which have embedded potential energy but also to distinct between those opportunities which have a potential value that is worth pursuing and those which do not (Sadler-Smith, 2016). This shall be further discussed and explored.

\section{Discussion}

Complex systems situate on a continuum of complexity from ordinary complexity that include Prigoginean systems, tornadoes, Bénard Cells, auto-catalytic reaction systems to emergent complexity including entrepreneurial process. 'Nonequilibrium systems can be described by their forces and requisite flows using the well-developed methods of network thermodynamics' (Schneider \& Kay, 1994, p. 35). What are the forces that act or motivate the entrepreneurs to shift into high gear to act in response to the sighted opportunity where the future state is not deterministic. The dissipative structures in the light of the restated second law of thermodynamics has shown that these dissipative structures self-organize through the fluctuations and instabilities in an irreversible bifurcations leading towards a generative emergence (Lichtenstein, 2020) where new order comes into being. The 'coming-into being' has four phases integrated into the theory of generative emergence which reveals the sequential conditions through which a new system emerges. The phases are (a) disequilibrium organizing and stress, (b) experiments and amplifications to a critical threshold, (c) emergence of a new entity, and (d) stabilizing the new system into a dynamic state (Lichtenstein, 2020). Similarly, entrepreneurship can be premised entirely in terms of thermodynamic forces, flows, stability (Kondepudi, 2012).

Entrepreneurship can therefore be described as an organized state by taking energy from outside itself, that is, from a larger encompassing system- the entrepreneurial ecosystem (Hartvigsen et al., 1998), harnessing the local available resources and enacting on the opportunity (through dissipation) to produce a lower entropy state to return and stabilize the system. Entrepreneurial venture can be viewed as a far-from-equilibrium dissipative structure that maintains its local level of organization, at the expense of producing entropy in the larger system of which it is part. If we view the opportunity in an open thermodynamic system, the thermodynamic imperative of the restated second law is that the system will strive to reduce this gradient by using all the resources and means available to the entrepreneurs. We have already shown that self-organizing processes (Stinchfield et al., 2013) are effective means of reducing gradients.

Self-organization in nonequilibrium systems is the cornerstone for entrepreneurial actions. Under nonequilibrium conditions, the entrepreneurial venturing state can become unstable and a transition to an organized structure can occur through dissipative structures. 'Such structures are similar to the oscillating chemical reactions and 
spatiotemporal patterns in chemical and other systems. Because entropy and free-energy dissipating irreversible processes generate and maintain these structures, these have been called dissipative structures.' (Kondepudi et al., 2020). In short, the presentment of the opportunity in a nonequilibrium state triggers self-organization and actions from the entrepreneurs who will move to dissipate the potential gradient existing in the opportunity to produce a lower entropy state and a stabler system with profit derived. In the study in (Kondepudi et al., 2020) their research revealed that some of these structures exhibit organism-like behaviour akin to the organism-like behaviours in electrically and chemically driven systems. This can be a breakthrough discovery as the behaviours of entrepreneurs is part of pattern formation responding to signals and stimuli. The spontaneity in the dissipative actions are not externally driven but by the internal system and therefore it is the spontaneity of the entrepreneurial behaviours that counts and that leads to the self-organization to dissipate the gradient to elicit the profits therein.

'Given that organisms are dissipative structures, there is likely a continuum of systems that spans from non-living to living dissipative systems. Dissipative structures studied for many decades starting from the 1970s provided insight into how biological form and pattern formation might emerge from nonequilibrium chemical systems (with appropriate autocatalytic and other mechanisms) and how irreversible chemical processes might provide "chemical clocks" and give rise to periodic phenomena in living systems. However, they did not have any bio-analogues that behaved like living systems and exhibited end-directed behaviours such as "foraging" and moving towards the source of energy that sustains it. In our recent work, we have identified such a system which is electrically driven. It is a "missing link" between dissipative structures and organisms: it exhibits organisms-like behaviours, but it is not a living organism. Such non-living dissipative structures, we propose, can serve as examples of the class of systems that bridges non-living and living dissipative systems. In these complex systems, several thermodynamic forces and flow are coupled.' (Kondepudi et al., 2020, p. 6). Kondepudi et al. (2020) studies of non-living dissipative structures have demonstrated a plethora of biologically plausible behaviours. Their bio-analogue dissipative structures (BDS) serve as minimally operative models for biology and a framework for understanding the physical foundations for a physics of organism and evolution of life. This can indeed be contextualized to entrepreneurship since entrepreneurial acts arise from the recognition of opportunities as the stimuli that invokes the operations of the dissipative structures. Dissipative structures have been theoretically proposed as models of psychological systems, involving cognitive motor control especially in the production of rhythmic movements (Kugler \& Turvey, 2015). In (Kondepudi et al., 2020, p. 7) 'studied two dissipative structures, an electrical and a chemical system, which we classify as self-organized foraging implementations (SOFIs). Our electrical system (E-SOFI) produces an array of life-like properties, including foraging, end-directed behaviours, structure maintenance and self-healing, and even functional coordination. The chemical system (C-SOFI) demonstrates flocking behaviours sensitivity to external thermal and magnetic fields, and collective navigation of environments. Several other groups in the field of dynamic self-assembly (DySA) have demonstrated similar life-like behaviours, including chemotaxis, collective dynamics, and self-healing.' These concepts as self-organized foraging implementations (bricolage, effectuation are activities of improvisations), end-directed behaviours (discovery), functional coordination (organization of space and integration of materials and resources), flocking behaviours (actions of imitators) can be presented as a typology of entrepreneurial behaviours. Themes such as organization of space, integration of materials, sense of personal limits, and responsiveness to changing market conditions are observable in entrepreneurship (Stinchfield et al., 2013).

\subsection{On Perception, Opportunity and Profit}

Embedded with opportunities are the perceived energy gradients waiting to be dissipated by alert entrepreneurs who will use all creative means to achieve the dissipation. Opportunities have to be meaningful for them to be first seen, recognized, identified, discovered, or created such that the process of dissipation through entrepreneurial actions will be triggered; opportunities can be viewed in many ways:

'For example, while some have viewed opportunity as something identified in a moment of insight that is the result of accidental discovery, others view the opportunity-related process as taking place over time, as the result of a systematic search or as enacted and constructed in the present. Some view it is a cognitive process that can involve mental simulation and counterfactual thinking, heuristics based logic, or maybe an effectuation process of forming, shaping, creating, or enacting an opportunity that emerges from within the entrepreneur. Similarly the opportunity-related process has been viewed as a creative process, involving creativity, or even as a special case of problem solving.' (Hansen et al., 2011, p. 285)

Whatever perspectives that are used to recognize, discover, identify, or create opportunities, the operative key is the ability to recognize the gradient and the opportunity's potential. 'The sifting and sorting and processing of an 
opportunity's potential plays out on a patently micro-level scale where a priori uncertainties cannot be hedged in advance of the entrepreneur taking action.' (Hansen et al., 2011, p. 36) Uncertainty is prevalent in all stages of the entrepreneurial venture setting to a larger or lesser degree as it is pervasive in entrepreneurial settings. The uncertainty of future conditions is dauting and unnerving to entrepreneurs. Uncertainty transitions throughout the entrepreneurial process and uncertainty shifts over time due to endogenous and exogenous change (Packard et al., 2017). Yet in other instances, the processes have been considered an innate trait where an entrepreneur has an alertness (Frese \& Gielnik, 2014) with a sharp capability to recognize opportunities with a risk-tolerance (Karabulut, 2016). It is far from consensus with regard to the definition of entrepreneurial opportunity and opportunity-related processes particularly the operationalization of it. There are varied independent variables such as uncertain environmental conditions as well as future conditions, cognitive ability to identify and recognize, risk-tolerance, so what really plays out when the entrepreneur senses the opportunity potential or energy gradient in a state of disequilibrium? Entrepreneur in self-organization mode moves in response to incentives created by the disequilibrium (Schultz, 1975).

Entrepreneurial venturing involves constant seeking of opportunities and dissipating the gradient through gradient-manipulation mechanism and the entrepreneur will adopt exploitative strategies and actions to maintain these dissipative structures in the face of a fluctuating physical environment which is in a state of disequilibrium. In the dynamic dissipative systems, finding the means to effectively dissipate the potential gradient to a profitable end, there are encoded memories like prior experience and knowledge (Hsu, 2011), that allow the dissipative processes to be engaged with better and higher chance for success.

\subsection{Opportunities Existing in Possibility Space Under Conditions of Uncertainties}

The possibility space in which the entrepreneurs operate provides the social and material networks, resources bundles (Lichtenstein \& Brush, 2001) and conditions for ventures. The entrepreneurs still must maintain a certain sharpness and entrepreneurial alertness (Ardichvili et al., 2003) (Karabulut, 2016) for the opportunities that may appear to exist in the possibility space. Whether through effectuation (Sarasvathy, 2009) (Stroe et al., 2018), bricolage, creation, co-creation (Garud et al., 2014), the key is that the entrepreneurs must see the potential in the opportunity. In this respect, all the debates on opportunities whether they exist, independent of perceptions of entrepreneurs, real and objective or waiting to be discovered or are they created by the actions of entrepreneurs (Alvarez \& Barney, 2007) they must be seen from the perspective of gradient manipulation. Discovery or creation, the larger question is what causes the entrepreneurial actions. What drives the action? The antecedent variables of discovery or creation, whether real or artificial as described by (Sarasvathy, 2003), in the minds of the entrepreneurs, they must recognize the energy gradients in those opportunities and look to the dissipation of the gradient to capitalize and monetize on that opportunity. The dissipative mechanism will be the set of entrepreneurial activities put together by the entrepreneurs to drive to the profitable end, through the play of the gradients, by exploitation (Adner \& Levinthal, 2008). This particular ability, as noted at the outset, represents the competence of entrepreneurs to recognize an opportunity in a given disequilibrium - and to evaluate its attributes properly in determining whether it is worthwhile to act, and if it is worthwhile, entrepreneurs respond by reallocating their resources. The realized gains from such reallocations from the endgame is the profits. 'The expected gains are the economic incentives to enter upon these equilibrating activities.' (Schultz, 1975, p. 83)

An interesting natural phenomenon is the stored energy in gradients described in (DeLanda, 2011). Such phenomenon can also be applied to opportunity recognition based on entrepreneurial alertness to business opportunities. Entrepreneurial alertness, in its turn, is a necessary condition for the success of the opportunity identification triad: recognition, development, and evaluation (Ardichvili et al., 2003). Entrepreneurs require the cognitive and affective temperaments and access to resources to be able to appraise the viability and potential, hence in this case assess the energy-gradient for value creation of a discovered opportunity (Sadler-Smith, 2016). Finally for opportunity exploitation (Shane \& Venkataraman, 2000) entrepreneurs must possess the motivational, cognitive, and abilities, skills, and resources to be able to engage in the exploitation of viable new discoveries. The exploitation must be through the mechanism of "lock" and "key" where the fit must eventually lead to the creation of the energy gradient for dissipation in the exploitative acts. In (DeLanda, 2011), it explains at the molecular level this interactivity:

'... molecular recognition, the simplest kind of which is a geometrical complementarity between two different molecules, one acting as a "lock" the other as a "key." Putting together these two capacities yields a catalyst. Metallic crystals, for example, can act as powerful catalysts: they can attach themselves to a molecule twisting it or otherwise deforming it; pushing it away from equilibrium and creating a gradient. This physical gradient is similar to those that exist in most load-bearing structures, such as buildings or bridges, in which the structural elements carrying the load are typically deformed- stretched if the load is carried in tension, shrunk if in 
compression- and are for that reason loaded with strain energy. After a metallic catalyst attaches to and deforms its target a step in a chemical reaction that was energetically uphill before the deformation is now downhill and will have a better chance of occurring spontaneously." It is the emergent autocatalytic loops in the gradient-dissipation (tension reliefs) that are the real solution to the problem and hence constitute the main play in the dissipative process in entrepreneurial drama- full of ups and downs, stops and starts, changes and transformations.' (DeLanda, 2011, p. 38)

\section{Thermodynamics Implications in Entrepreneurship}

In this paper, we are constructing an agent-centric, self-organizing agent, being the main cast, in creating generalizable and agreeable model based on thermodynamic principles to describe entrepreneurial dynamics. The recognition of perpetual novelty and out-of-equilibrium dynamics are the cornerstones of this model. Each new emerged dynamic state is caused by Lichtenstein's "opportunity tension" (Lichtenstein, 2009) or perturbations -described as either shocks, triggers or stressors since these perturbations add to the degree of disequilibrium and implicit tensions- which are the driver of order creation. Entrepreneurs therefore are subject to constant barrage of disturbances and white noises in their social ecosystem and have to tolerate sustained disequilibrium and to be constantly in search of opportunity tensions to derive profits from exploitative actions such as arbitrage. Entrepreneurs' actions predicate on calculable outcomes in a marketplace where entropy reigns supreme. The second law of thermodynamics states that entropy always increases with time. Entropy is defined as a thermodynamic quantity representing the unavailability of a system's thermal energy for conversion into mechanical work, often interpreted as the degree of disorder or randomness in the system. Entrepreneurial process has similarities which are phenomenological manifestations of the second law of thermodynamics (Schneider \& Kay, 1994). To cast the second law of thermodynamics in entrepreneurial terms, the re-cast second law therefore suggests that as the entrepreneurial system moved away from equilibrium, in state of flux and perpetual disequilibrium, the system will take advantage of all available means to resist externally applied gradients. The actions of resistance create the motion and the movement along the process over time. Note that these are the same gradients (measure of the steepness of the curve) that give rise to tensions as they present arbitrage-able and exploitative opportunities. When higher order complex system emerges, the system naturally develops and grows at the expense of increasing disorder at higher levels of the system's hierarchy (Schneider \& Kay, 1994) and the semblances to entrepreneurial process is worth the mention and study. The behaviour of the system can be observed naturally in physical and chemical systems.

In a sense, as coined in (Lichtenstein, 2009) "energy-conversation system" or can be variously referred to energy exchange and transactions in the system, the motion and movement along the process is spurred by the energy exchange. In this section, we are premising our discussion on the energy exchange. In (Schneider \& Kay, 1994), "as ecosystems grow and develop, they should increase their total dissipation, develop more complex structures with more energy flow, increase their cycling activity, develop greater diversity and generate more hierarchical levels, all to abet energy degradation. Species which survive in ecosystems are those that funnel energy into their own production and reproduction and contribute to autocatalytic processes which increase the total dissipation of the ecosystem. In short, ecosystems develop in ways which systematically increase their ability to degrade the incoming solar energy. We believe that our thermodynamic paradigm makes it possible for the study of ecosystems to be developed from a descriptive science to predictive science founded on the most basic principle of physics." To translate and to make it relevant to our context of entrepreneurial venturing, the entrepreneur venture growing and developing in the space of ecosystem with the socio-material network, the venture necessarily increases their total dissipation. Their emergence -with entrepreneurial events- into the future are contingent on the exploitative actions and set of activities. These activities are the "autocatalytic processes- that increase the total dissipation of the gradients. The energy-conversations and exchanges throughout the process create this motion and movement along the entrepreneurial sine-curve. The entrepreneurial venture can thus harness the energy from the ecosystem to create greater diversity and generate higher hierarchical levels so that the venture does not suffer energy degradation (in entrepreneurial term, losses).

There is an extract from (Schneider \& Kay, 1994) that aptly summarizes the energy-conversation, the play of the gradients in nonequilibrium processes:

"However, Schrodinger's equally important and less understood observation was his "order from disorder" premise. This was an effort to link biology with the fundamental theorems of thermodynamics. He noted that at first glance, living systems seem to defy the second law of thermodynamics as it insists that, within closed systems, entropy should be maximized and disorder should reign. Living systems, however, are the antithesis of such disorder. They display marvellous levels of order created from disorder. For instance, plants are highly ordered structures, which are synthesized from disordered atoms and molecules found in atmospheric gases and 
soils. Schrodinger solved this dilemma by turning to nonequilibrium thermodynamics, that is, he recognized that living systems exist in a world of energy and material fluxes. An organism stays alive in its highly organized state by taking energy from outside itself, from a larger encompassing system, and processing it to produce, within itself, a lower entropy, more organized state. Schrodinger recognized that life is a far-from-equilibrium system that maintains its local level of organization at the expense of the larger global entropy budget. He proposed that to study living systems from a nonequilibrium perspective would reconcile biological self-organization and thermodynamics. Furthermore, he expected that such a study would yield new principles of physics. This paper takes on the task proposed by Schrodinger and expands on his thermodynamic view of life. We explain that the second law of thermodynamics is not an impediment to the understanding of life but rather is necessary for a complete description of living processes. We further expand thermodynamics into the causality of the living process and assert that the second law is a necessary but not sufficient cause for life itself. In short, our re-examination of thermodynamics shows that the second law underlies and determines the direction of many of the processes observed in the development of living systems. This work harmonizes physics and biology at the macro level and shows that biology is not an exception to physics, we have simply misunderstood the rules of physics." (Schneider \& Kay, 1994, p. 26)

To translate to entrepreneurial terms, the entrepreneurial process draws energy (from recognition of opportunity tension to point of exploitation - relieving the tension to profit derivation) from outside space, which is the ecosystem full with socio-material networks and resource bundles which is a larger encompassing system than the entrepreneurial process. On drawing the energy, inputs of resources through co-creation, bricolage or structuration (Selden \& Fletcher, 2015), the entrepreneurial process will produce, within itself a lower entropy vis a vis outside (ecosystem) and a more organized state through the activity of self-organization. The self-organization and the thermodynamics mechanism produce a flow of entrepreneurial energy (Leong, 2021) fluxes through the entrepreneurial process over time. Thermodynamics can therefore explain the causality of the entrepreneurial process and its unidirectionality, non-reversibility, nonlinearity, discontinuity in a nonequilibrium environment. Away from the state of equilibrium, in a nonequilibrium external environment, highly ordered stable complex systems can emerge, develop and grow at the expense more disorderliness at higher levels in the system's hierarchy. In short, the higher the disorderliness, the steeper the gradients and the process is about harnessing the differentials in the gradients for profits. Entrepreneurial venturing is thus, in summary, the play of the gradients.

\section{Dissipation, Gradient Manipulation and Tension Reliefs}

The discussion on how thermodynamic gradients drive self-organization is the core of this conceptualization in relations to entrepreneurship and to explore the natural force that drives entrepreneurial actions. Entrepreneurial motion and movement along the venture pathway can be seen as a high-dimensional complex manoeuvres influenced by many variables from opportunity recognition to exploitation (Sadler-Smith, 2016) and motivated by entrepreneurial passions (Cardon et al., 2017). The emergence, acted up by the thermodynamic mechanism strive to reduce the gradients (opportunity tension) by all processes available to them. In this section, we go on to argue that gradient manipulation and tension reliefs can make further progress by taking a more 'naturalistic' or natural science approach to entrepreneurship theorization. This requires that the analysis be fully embedded in complexity science theory and thermodynamics laws in establishing understandings as to how entrepreneurs react to states of uncertainty and how they explicitly deal with opportunities, risks and uncertainties. The argument is that 'knowledge,' because of the existence of uncertainty is, to a large degree conjectural and on "best guess" basis thus, is closely linked to our emotional states including the entrepreneurial passions that drive action described in (Frese \& Gielnik, 2014) (Fisher, 2011). Entrepreneurial behaviour is also influenced by the reality that they create and co-create and by virtue of this set of behaviour, they are dissipative structures. This section will explore the notions of 'energy gradients' and 'knowledge gradients' as essential concepts in understanding entrepreneurial emergence and resultant venture pathway development.

Entrepreneurial systems are dissipative structures and to understand them, we need to understand the nature of the boundary - the interaction between the entrepreneur as the main cast with the ecosystem because it is at the boundary of that interactions occur. Emergence occurs in an ecology of resources and conditions. An ecological system reflects the essence of emergence including high interdependence, nonlinearity and self-organization. Entrepreneurial ecologies lead to powerful emergent effects (Lichtenstein, 2011). Applications of thermodynamic principles to the science of ecology can bring compelling similarities to the entrepreneurial ecosystem. As a natural phenomenon, natural existing ecosystem are open thermodynamic systems with a large gradient impressed on them by the sun (Schneider \& Kay, 1994). Schneider and Kay further add that: 
“... the thermodynamic imperative of the restated second law is that these systems will strive to reduce this gradient by all physical and chemical processes available to them. Thus, ecosystems will develop structures and functions selected to most effectively dissipate the gradients imposed on them while allowing for the continued existence of the ecosystem. We examine one ecosystem closely and using analyses of carbon flows in stressed and unstressed conditions, we show that the unstressed ecosystem has structural and functional attributes that lead to more effective degradation of the energy entrained within the ecosystem. Patterns of ecosystem growth, cycling, trophic structure and efficiencies are explained by this paradigm." (Schneider \& Kay, 1994, p. 35)

The gradient manipulation is therefore a profit-seeking mechanism where the entrepreneurs seek to dissipate the gradients in opportunities. Entrepreneur's move to action is therefore contingent on this dissipation effect.

This distinctive relationship between operating within uncertainty and the profit-seeking mechanism makes entrepreneurship unique within the social sciences. The presence of a priori uncertainty regarding the viability and feasibility of an entrepreneurial opportunity is in some sense an essential pre-condition for the very existence of the opportunity. On the entrepreneur's volition and willingness to bear uncertainty is a critical determinant of the generative path or emergence and that ultimately transpire to a set of entrepreneurial actions in the dissipative structures.

Drawing on the disparate literatures within entrepreneurship and outside of the usual economics literatures into the realm of physics, in particular thermodynamics, it can be argued that entrepreneurial venturing should be more properly viewed as the outcome of a co-evolutionary, co-creation process that involves the autocatalytic interaction of new knowledge together with past experience and access of resources (these can be the input resources in the socio-material networks) to have a continuous stream of emergence that drive entrepreneurial process and to extend the play of the entrepreneurial sine-curve.

\subsection{Dissipative Structures and Its Relevant to Entrepreneurship}

The relevance and applicability of thermodynamic laws to entrepreneurial system needs further elaboration as this section discusses dissipative structures and will introduce how the energy gradients play a role in the capitalization or profit derivation in a space-time chaos existing in the entrepreneurial ecosystem. When we invoke the notion of energy, we must therefore be concerned about its origin, its flow its propagation and any characterization of the physics description of energy (Schrödinger, 2003). The 'energy hypothesis,' so closely linked to Erwin Schrödinger need to be reinterpreted and re-casted to entrepreneurial energy (Leong, 2021) to fill the gap in entrepreneurial study. What flows in the entrepreneurial process? The opportunity tension (Lichtenstein, 2007) capture the "pulses" in each cycle leading to a new dynamic state. What are the pulses referred in (Lichtenstein, 2007)?

The concept of dissipative structures, from the field of complexity theory, is borrowed to develop and explain a specific sequence and pattern of activities which underpin effective entrepreneurial change and transformation in the entrepreneurial process. This section will explore the entrepreneurs' behaviours arising from the emergent properties of the system. The spatial-temporal chaos in the external environment/ entrepreneurial ecosystem is the starting point of the venturing process. Chaos has within it determinable risks and uncertainties, differentiated by Knight in (Knight, 1921)(Khalil, 1997). The risks, particularly absolute uncertainty do not prevent entrepreneurial venturing from occurring (Foster \& Metcalfe, 2012) but it draws on the uncertainties and differentials through destruction and creative creation and co-creation including reorganizing resources and recombinants (Bessant, \& Trifilova, 2017) that gives rise to entrepreneurial emergence or generative emergence in (Lichtenstein, 2014a). With the varying degrees of risks and uncertainties, entrepreneurs operate within the ever-changing complex system and need to have creative and innovative ways to see, capitalize, combine, recombine the bundle of resources available in the specific space-time. In short, entrepreneurs are dealing with complex adaptive systems with particular kinds of self-organizing features (Foster \& Metcalfe, 2012).

Dissipative structures generate new types and levels of entrepreneurial order that emerge in disequilibrium situations through self-amplifying process sparked by fluctuations. Entities generate new order by dissipating large amount of energy, information and resources (Lichtenstein, 2011). This hypothesis states that all dissipative structures have, as their primary objective, the reduction of accessible free energy gradients (Foster, 2011). So the question is this energy propounded in the theorization by (Lichtenstein, 2014b) (Fuller \& Moran, 2001)(Ireland \& Gorod, 2016) true entrepreneurial energy (Leong, 2020)? Enacting under conditions for emergence, destruction and creation with the rich and deep nonlinear interactions in the relational space (holographically), dealing with opportunity tension, reducing the accessible free energy gradients and integrating 
the conditions for emergence (enfolding or implicate order as described by Bohm (Bohm \& Fowler, 1978)), energy must therefore necessarily exist (Leong, 2020) in the entrepreneurial process. The applications of the laws of thermodynamics have been used to model complex physical fluid turbulence and dynamics. In fact, the behaviours of entrepreneurs on close examination do emulate fluid dynamics operating under the thermodynamic principles. Thermodynamics principles, in particular entropy do provide substantial clarity to the entrepreneurial processual framework. Entrepreneurs who survive in the ecosystem are those that funnel energy (input resources) into their exploitative activities including their own production and reproduction on existing resources and recombinant (Bessant, \& Trifilova, 2017) to contribute to the autocatalytic process which increase the total dissipation of the system.

The structure and processes of entrepreneurship are driven and maintained by irreversible processes. Though the particular process of self-organization, in both thermodynamics and entrepreneurial terms, which is setting in motion a series of entrepreneurial actions and activities or 'self-organized foraging implementations' have resulted in the familiar patterns formation and they are undoubtedly dissipative structures, given that their existence and behaviours are sustained by continuous flows of energy and the dissipation of that energy gradients - in obvious moves to achieve profits and towards profitability. 'Modern thermodynamics has the tools of forces, flows, and rates of entropy production that can be used to understand biological processes. In line with a number of theorists, we hold that living systems are a subset of the class of dissipative structures, and that their origin, behaviours, and evolution are critically related to their thermodynamic properties.' (Kondepudi et al., 2020, p. 4)

\section{Conclusion}

These thermodynamics and gradient-manipulation mechanisms bring us closer to a resolving some of the puzzles in explaining entrepreneurial motivations and actions in exploration-exploitation. Entrepreneurship researches need a comprehensive and unifying theory that can bind the current frameworks, paradigms and models. The processual aspect of entrepreneurial research at the holistic level should be emphasized. The scientific discourse in this paper adds much to our processual understanding of entrepreneurship. Such observations of the natural phenomena can give sharper definition to those spontaneous self-organization actions and the intuitive (Sadler-Smith, 2016) bets by entrepreneurs when they are in absolute uncertainties and what actually draw them to the opportunities. From the perspective of energy gradient-manipulations, the theorizing of entrepreneurship reinforces the notion of 'emergence'. Generative emergence (Lichtenstein, 2014a) on the process of entrepreneurship should receive more scholarly attention.

Patterns in nonequilibrium systems tend to be time- dependent and irregular endlessly changing from one structure to another, in a rather unpredictable way which is similar to the generative emergence phenomenon expounded by Lichtenstein in (Lichtenstein, 2014). 'More recently, in the mid-to-late 20th century, researchers used high-precision, detailed experiments to try to establish a unifying theory of nonequilibrium thermodynamics that would bring formalism to the field: something like the case of statistical mechanics, which provides a molecular explanation for equilibrium behaviour.' (Ornes, 2017, p. 424) and so it is hoped that in this paper, we can establish the connectedness and relationship between entrepreneurial process and nonequilibrium thermodynamics rationales

In the process, we hope to have shown why nonequilibrium thermodynamics process is essential not only to the study of the entrepreneurial phenomenon but also how thermodynamics and gradient manipulation mechanism can unify the phenomenon of entrepreneurial action in the field of entrepreneurship; with entrepreneurial energy being the manifestation in the emergence theorization. The thermodynamics paradigm that are applied to physical, biological and chemical systems can be applied to the entrepreneurial system- with thermodynamically consistent explanations for the development of far-from-equilibrium complex systems in entrepreneurial ventures.

At the end, the "invisible hand" and mystery forces may just be the thermodynamics forces and flow hence it is hoped that scholars may conduct further researches into entrepreneurship along this direction.

\section{References}

Adner, R., \& Levinthal, D. (2008). Doing versus seeing: acts of exploitation and perceptions of exploration. Strategic Entrepreneurship Journal, 2(1), 43-52. https://doi.org/10.1002/sej.19

Alvarez, S. A., \& Barney, J. B. (2007). Discovery and creation: alternative theories of entrepreneurial action. Strategic Entrepreneurship Journal, 1(1-2), 11-26. https://doi.org/10.1002/sej.4

Ardichvili, A., Cardozo, R., \& Ray, S. (2003). A theory of entrepreneurial opportunity identification and 
development. Journal of Business $\quad$ Venturing, $18(1), \quad$ 105-123. https://doi.org/10.1016/S0883-9026(01)00068-4

Atuahene-Gima, K. (1996). Market Orientation and Innovation. Journal of Business Research, 35.

Benyamin Lichtenstein, A. B., \& Lichtenstein Lichtenstein, B. B. (2009). Moving far from far-from-equilibrium: Opportunity tension as the catalyst of emergence* Moving far from far-from-equilibrium: Opportunity tension as the catalyst of emergence*. Emergence: Complexity and Organization. https://doi.org/10.emerg/10.17357.a6caf4674b89c48ca05dd0bb8cec7b81

Bessant, J., \& Trifilova, A. (2017). Developing absorptive capacity for recombinant innovation. . Business Process Management Journal, 23(6), 1094-1107. .

Boettke, P. J., \& Sautet, F. E. (2012). The Genius of Mises and the Brilliance of Kirzner. SSRN Electronic Journal. https://doi.org/10.2139/ssrn.1753343

Bohm, D., \& Fowler, D. R. (1978). The Implicate Order. Process Studies, 8(2), 73-102. https://doi.org/10.5840/process 19788222

Bygrave, W. D. (1993). Theory building in the entrepreneurship paradigm. Journal of Business Venturing, 8(3), 255-280. https://doi.org/10.1016/0883-9026(93)90031-Y

Cardon, M. S., Glauser, M., \& Murnieks, C. Y. (2017). Passion for what? Expanding the domains of entrepreneurial passion. Journal of Business Venturing Insights, 8, 24-32. https://doi.org/10.1016/j.jbvi.2017.05.004

Chia, R. (1999). A "Rhizomic" Model of Organizational Change and Transformation: Perspective from a Metaphysics of Change. British Journal of Management, 10(3 SPEC. ISS.), 209-227. https://doi.org/10.1111/1467-8551.00128

Cohen, B., Smith, B., \& Mitchell, R. (2008). Toward a sustainable conceptualization of dependent variables in entrepreneurship research. Business Strategy and the Environment, 17(2), 107-119. https://doi.org/10.1002/bse.505

Dana, L. P., Etemad, H., \& Wright, R. W. (2008). Toward a paradigm of symbiotic entrepreneurship. International Journal of Entrepreneurship and Small Business, 5(2), 109-126. https://doi.org/10.1504/IJESB.2008.016587

Davidsson, P., \& Gruenhagen, J. H. (2020). Fulfilling the Process Promise: A Review and Agenda for New Venture Creation Process Research. Entrepreneurship: Theory and Practice, 1-36. https://doi.org/10.1177/1042258720930991

De Bari, B., Kondepudi, D. K., Kay, B. A., \& Dixon, J. A. (2020). Collective Dissipative Structures, Force Flow Reciprocity, and the Foundations of Perception-Action Mutuality. Ecological Psychology, 32(4), 153-180. https://doi.org/10.1080/10407413.2020.1820337

DeLanda, M. (2011). Philosophy and simulation: the emergence of synthetic reason. Bloomsbury Publishing.

Dew, N., Sarasathy, S., Read, S., \& Wiltbank, R. (2009). Affordable loss: behavioral economic aspects of the plunge decision. Strategic Entrepreneurship Journal, 3(2), 105-126. https://doi.org/10.1002/sej.66

Fisher, R. (2011). Passion, Resilience, Obsession \& Sustained Entrepreneurial Action: the Path to Entrepreneurial Success.

Foot, P. (1957). Free will as involving determinism. The Philosophical Review, 66(4), 439-450.

Foster, J. (2011). Energy, aesthetics and knowledge in complex economic systems. Journal of Economic Behavior and Organization, 80(1), 88-100. https://doi.org/10.1016/j.jebo.2011.02.013

Foster, J., \& Metcalfe, J. S. (2012). Economic emergence: An evolutionary economic perspective. Journal of Economic Behavior \& Organization, 82(2-3), 420-432. https://doi.org/10.1016/j.jebo.2011.09.008

Frese, M., \& Gielnik, M. M. (2014). The Psychology of Entrepreneurship. In Annual Review of Organizational Psychology and Organizational Behavior (Vol. 1, pp. 413-438). Annual Reviews Inc. https://doi.org/10.1146/annurev-orgpsych-031413-091326

Fuller, T., \& Moran, P. (2001). SMALL FIRMS AS COMPLEX ADAPTIVE SYSTEMS: A REVIEW. https://www.researchgate.net/publication/237227921

Garud, R., Gehman, J., \& Giuliani, A. P. (2014). Contextualizing entrepreneurial innovation: A narrative 
perspective. Research Policy, 43(7), 1177-1188. https://doi.org/10.1016/j.respol.2014.04.015

Hansen, D. J., Shrader, R., \& Monllor, J. (2011). Defragmenting Definitions of Entrepreneurial Opportunity. Journal of Small Business Management, 49(2), 283-304. https://doi.org/10.1111/j.1540-627X.2011.00325.x

Hartvigsen, G., Kinzig, A., \& Peterson, G. (1998). Use and analysis of complex adaptive systems in ecosystem science: Overview of special section. Ecosystems, 1(5), 427-430. https://doi.org/10.1007/s100219900036

Hattwick, R. E. (1979). Competition and entrepreneurship. Journal of Behavioral Economics, 8(2), 183-188. https://doi.org/10.1016/0090-5720(79)90011-1

Hsu, D. K. (2011). Toward a Theory of Serial Entrepreneurship: Decomposing Entrepreneurial Experience. ProQuest Dissertations and Theses.

Huang, L., \& Pearce, J. L. (2015). Managing the Unknowable: The Effectiveness of Early-stage Investor Gut Feel in Entrepreneurial Investment Decisions. In Administrative Science Quarterly (Vol. 60, No. 4). https://doi.org/10.1177/0001839215597270

Ireland, R. D., Kuratko, D. F., \& Covin, J. G. (2003). Antecedents, Elements, And Consequences Of Corporate Entrepreneurship Strategy. Academy of Management Proceedings, (1), L1-L6. https://doi.org/10.5465/ambpp.2003.13793054

Ireland, V., \& Gorod, A. (2016). Contribution of complex systems to entrepreneurship. In Entrepreneurship Research Journal (Vol. 6, No. 1, pp. 1-41). Walter de Gruyter GmbH. https://doi.org/10.1515/erj-2015-0058

Karabulut, A. T. (2016). Personality Traits on Entrepreneurial Intention. Procedia - Social and Behavioral Sciences, 229, 12-21. https://doi.org/10.1016/j.sbspro.2016.07.109

Khalil, E. L. (1997). Chaos Theory Versus Heisenberg's Uncertainty: Risk, Uncertainty and Economic Theory. The American Economist, 41(2), 27-40. https://doi.org/10.1177/056943459704100204

Kirzner, I. M. (1973a). Competition and entrepreneurship.

Kirzner, I. M. (1973b). Competition and Entrepreneurship. University of Chicago Press.

Knight, F, . (1921). Risk, uncertainty and profit. . New York: Augustus Kelley.

Kondepudi, D. (2012). Self-Organization, Entropy Production, and Physical Intelligence. Ecological Psychology, 24(1), 33-45. https://doi.org/10.1080/10407413.2012.643716

Kondepudi, D. K., De Bari, B., \& Dixon, J. A. (2020). Dissipative Structures, Organisms and Evolution. Entropy, 22(11), 1305. https://doi.org/10.3390/e22111305

Kugler, P. N., \& Turvey, M. T. (2015). Information, natural law, and the self-assembly of rhythmic movement. In Routledge. Routledge.

Leong, D. (2020). Entrepreneurial Energy and Opportunities Existing in Space. Journal of Entrepreneurship, Business and Economics, 8(2), 196-218. http://scientificia.com/index.php/JEBE/article/view/144

Leong, D. (2021). Entrepreneurial Energy in a Far-From-Equilibrium Opportunity Driving Entrepreneurial Actions. Journal of Entrepreneurship, Business and Economics, 9(1), 1-31. http://www.scientificia.com/index.php/JEBE/article/view/143

Lichtenstein, B. (2020). Generative Emergence: Research and Praxis for Social Innovation. In Oxford Research Encyclopedia of Psychology. Oxford University Press. https://doi.org/10.1093/acrefore/9780190236557.013.735

Lichtenstein, B. B. (2007). Moving Far From Far-From-Equilibrium: Opportunity Tension as the Driver of Emergence. Organization Science Winter Conference. http://scholarworks.umb.edu/management_wphttp://scholarworks.umb.edu/management_wp/13

Lichtenstein, B. B. (2011). Complexity Science Contributions to the Field of Entrepreneurship. In Benyamin B Lichtenstein The Sage handbook of complexity and management, 471-493. https://www.researchgate.net/publication/228597717

Lichtenstein, B. B. (2014a). Generative Emergence. Oxford: Oxford University Press. https://www.researchgate.net/publication/263297956

Lichtenstein, B. B. (2014b). Generative Emergence. Generative Emergence, July. https://doi.org/10.1093/acprof:oso/9780199933594.001.0001

Lichtenstein, B. M. B., \& Brush, C. G. (2001). How Do "Resource Bundles" Develop and Change in New 
Ventures? A Dynamic Model and Longitudinal Exploration. Entrepreneurship Theory and Practice, 25(3), 37-58. https://doi.org/10.1177/104225870102500303

McKelvey, B. (2001). What Is Complexity Science? It Is Really Order-Creation Science. Emergence, 3(1), 137-157. https://doi.org/10.1207/S15327000EM0301_09

McKelvey, B. (2004). Toward a complexity science of entrepreneurship. Journal of Business Venturing, 19(3), 313-341. https://doi.org/10.1016/S0883-9026(03)00034-X

McKenzie, L. W. (1981). The Classical Theorem on Existence of Competitive Equilibrium. Econometrica, 49(4), 819. https://doi.org/10.2307/1912505

Mises, Ludwig Von. (1949). Human action: A treatise on economics (4th revised ed.). In San Francisco: Fox \& Wilkes.

Ornes, S. (2017). How nonequilibrium thermodynamics speaks to themystery of life. Proceedings of the National Academy of Sciences of the United States of America, 114(3), 423-424. https://doi.org/10.1073/pnas.1620001114

Packard, M. D., Clark, B. B., \& Klein, P. G. (2017). The Types of Uncertainty Entrepreneurs Face. UNCERTAINTY TYPES AND TRANSITIONS IN THE ENTREPRENEURIAL PROCESS.

Pitelis, C. (2012). Clusters, entrepreneurial ecosystem co-creation, and appropriability: A conceptual framework. Industrial and Corporate Change, 21(6), 1359-1388. https://doi.org/10.1093/icc/dts008

Prigogine, I. (1978). Time, Structure, and Fluctuations. Science, 201(4358), 777-785. https://doi.org/10.1126/science.201.4358.777

Prigogine, I., \& Lefever, R. (1968). Symmetry breaking instabilities in dissipative systems. II. The Journal of Chemical Physics, 48(4), 1695-1700. https://doi.org/10.1063/1.1668896

Ramoglou, S, ., \& Tsang, E, . (2015). A Realist Perspective of Entrepreneurship: Opportunities as Propensities. Academy of Management Review, 41(3), 410-434. .

Sadler-Smith, E. (2016). The role of intuition in entrepreneurship and business venturing decisions. European Journal of Work and Organizational Psychology, 25(2), 212-225. https://doi.org/10.1080/1359432X.2015.1029046

Sarasvathy, S. D. (2003). Entrepreneurship as a science of the artificial. Journal of Economic Psychology, 24(2), 203-220. https://doi.org/10.1016/S0167-4870(02)00203-9

Sarasvathy, S. D. (2009). Effectuation: Elements of entrepreneurial expertise. Edward Elgar Publishing.

Schindehutte, M., \& Morris, M. H. (2009). Advancing Strategic Entrepreneurship Research: The Role of Complexity Science in Shifting the Paradigm.

Schneider, E. D., \& Kay, J. J. (1994). Life as a manifestation of the second law of thermodynamics. Mathematical and Computer Modelling, 19(6-8), 25-48. https://doi.org/10.1016/0895-7177(94)90188-0

Schrödinger, E. (2003). Collected papers on wave mechanics. American Mathematical Soc.., 302.

Schultz, T. (1975). The Value of the Ability to Deal with Disequilibria. Journal of Economic Literature, 13(3), $827-846$.

Selden, P. D., \& Fletcher, D. E. (2015). The entrepreneurial journey as an emergent hierarchical system of artifact-creating processes. Journal of Business Venturing, 30(4), 603-615. https://doi.org/10.1016/j.jbusvent.2014.09.002

Shane, S., \& Venkataraman, S. (2000). The Promise of Enterpreneurship as a Field of Research. In Source: The Academy of Management Review (Vol. 25, Issue 1).

Shepherd, D. A., Douglas, E. J., \& Shanley, M. (2000). New venture survival: Ignorance, external shocks and risk reduction strategies. Journal of Business Venturing, 15(5-6), 393-410. https://doi.org/10.1016/S0883-9026(98)00032-9

Shir, N., Nikolaev, B. N., \& Wincent, J. (2019). Entrepreneurship and well-being: The role of psychological autonomy, competence, and relatedness. Journal of Business Venturing, 34(5), 105875. https://doi.org/10.1016/j.jbusvent.2018.05.002

Stinchfield, B. T., Nelson, R. E., \& Wood, M. S. (2013). Learning From Levi-Strauss' Legacy: Art, Craft, Engineering, Bricolage, and Brokerage in Entrepreneurship. Entrepreneurship: Theory and Practice, 37(4), 
889-921. https://doi.org/10.1111/j.1540-6520.2012.00523.x

Stroe, S., Parida, V., \& Wincent, J. (2018). Effectuation or causation: An fsQCA analysis of entrepreneurial passion, risk perception, and self-efficacy. Journal of Business Research, 89, 265-272. https://doi.org/10.1016/j.jbusres.2018.01.035

Townsend, D. M., Hunt, R. A., McMullen, J. S., \& Sarasvathy, S. D. (2018). Uncertainty, knowledge problems, and entrepreneurial action. Academy of Management Annals, 12(2), 659-687. https://doi.org/10.5465/annals.2016.0109

Von Mises, L. (1949). Human Action: a Treatise on Economics. https://doi.org/10.2307/2605641

Watson, G. (1987). Free action and free will. Mind, 96(382), 145-172.

Wei, X., Cang, S., \& Hisrich, R. D. (2015). Entrepreneurial Stressors as Predictors of Entrepreneurial Burnout. Psychological Reports, 116(1), 74-88. https://doi.org/10.2466/01.14.PR0.116k13w1

Weick, K. E., \& Quinn, R. E. (1999). Organizational Change and Development. Annual Review of Psychology, 50(1), 361-386. https://doi.org/10.1146/annurev.psych.50.1.361

Wiklund, J., Nikolaev, B., Shir, N., Foo, M. Der, \& Bradley, S. (2019). Entrepreneurship and well-being: Past, present, and future. Journal of Business Venturing, 34(4), 579-588. https://doi.org/10.1016/j.jbusvent.2019.01.002

\section{Copyrights}

Copyright for this article is retained by the author(s), with first publication rights granted to the journal.

This is an open-access article distributed under the terms and conditions of the Creative Commons Attribution license (http://creativecommons.org/licenses/by/4.0/). 